\title{
A Propose for a Quadrature - Phase as Full Orthogonal Matrix Transform Compared with FFT Matrix Multiplication and Applied in OFDM System (Safe Transform the Fourier Twins)
}

\author{
* Saifuldeen Abdulameer Mohammed \\ Electrical Engineering Department College of Engineering, University of Baghdad \\ Baghdad,Iraq,msc_eng@yahoo.com
}

\begin{abstract}
In this paper, we will introduce a set of fully-orthogonal matrices for a transform that is more orthogonal than the Fast Fourier Transform (FFT), and prove that they are orthogonal for all rows and columns, as well as for each element and its neighbor elements, the basic matrix for this transform is founded upon the Quadrature -phase mapper principle, and can be extended by using the Hadamard matrix, this will provide orthogonality for all rows, columns and even single elements it will seen that the sum of all element be zero and applied in OFDM [1]system.
\end{abstract}

Keywords: Orthogonality; FFT matrix; OFDM.

\section{Introduction}

Objective of the research is to find easy replacement configuration instead of Fast Fourier transform matrix, As the sum of the matrix is not equal to zero it a new requirement was added in the terms of orthogonal matrices in this paper, Here we begin with the most famous orthogonal matrix with complex elements, that is the Fast Fourier transform (FFT) multiplication matrix for 4 elements [2,3,4], of $4 \times 4$ dimensions, the matrix of Fast Fourier Transform matrix multiplication with reconstruction below $4 \times 4$ then:

$\mathrm{FFT}_{\mathrm{m}}=\left(\begin{array}{llll}\mathrm{w}_{4}^{0} & \mathrm{w}_{4}^{0} & \mathrm{w}_{4}^{0} & \mathrm{w}_{4}^{0} \\ \mathrm{w}_{4}^{0} & \mathrm{w}_{4}^{1} & \mathrm{w}_{4}^{2} & \mathrm{w}_{4}^{3} \\ \mathrm{w}_{4}^{0} & \mathrm{w}_{4}^{2} & \mathrm{w}_{4}^{4} & \mathrm{w}_{4}^{6} \\ \mathrm{w}_{4}^{0} & \mathrm{w}_{4}^{3} & \mathrm{w}_{4}^{6} & \mathrm{w}_{4}^{9}\end{array}\right)=\left(\begin{array}{rrrr}1 & 1 & 1 & 1 \\ 1 & -\mathrm{j} & -1 & \mathrm{j} \\ 1 & -1 & 1 & -1 \\ 1 & \mathrm{j} & -1 & -\mathrm{j}\end{array}\right)$

Where: $\mathrm{W}_{\mathrm{N}}^{\mathrm{n}}=\mathrm{e}^{\left(-\frac{\mathrm{i} 2 \pi}{\mathrm{N}}\right) * \mathrm{n}}$

To prove that this matrix is orthogonal, we have to multiply it with its conjugate transpose, and check whether the product is really a scalar multiple of the identity matrix $[2,3,4]$, i.e.

$\mathrm{FFT}_{\mathrm{m}} * \mathrm{FFT}_{\mathrm{m}}^{* \mathrm{~T}}=\mathrm{K} * \mathrm{I}$

Or 
International Journal of

Soft Computing And Software Engineering (JSCSE)

e-ISSN: 2251-7545

Vol.2,No.6, 2012

Published online: Jun 17, 2012

$\mathrm{FFT}_{4 \times 4} * \mathrm{FFT}_{\mathrm{m} 4 \times 4}^{* \mathrm{~T}}=\left(\begin{array}{rrrr}1 & 1 & 1 & 1 \\ 1 & -\mathrm{j} & -1 & \mathrm{j} \\ 1 & -1 & 1 & -1 \\ 1 & \mathrm{j} & -1 & -\mathrm{j}\end{array}\right) *\left(\begin{array}{rrrr}1 & 1 & 1 & 1 \\ 1 & -\mathrm{j} & -1 & \mathrm{j} \\ 1 & -1 & 1 & -1 \\ 1 & \mathrm{j} & -1 & -\mathrm{j}\end{array}\right)=4 * \mathrm{I}$

Based on that result, the inverse matrix for $\mathrm{FFT}_{\mathrm{m}}$ is given by $[2,3,4]$ :

$\mathrm{FFT}_{\mathrm{m}}^{-1}=\frac{\mathrm{FFT}_{\mathrm{m}}^{* \mathrm{~T}}}{\mathrm{k}}$

Where $\mathrm{k}$ here happens to be equal to the dimension of the matrix itself.

\section{Basic Conditions}

In this paper, we intend to find a $(n \times n)$ matrix that satisfies all the following conditions:

1- $S_{(i, j)}=(r, \theta)$, Then $S_{(i+1, j)}=\left(r, \theta \pm \frac{\pi}{2}\right)$.

2- $\quad$ And $S_{(i, j+1)}=(r, \theta \pm \pi / 2)$.

3- $\mathrm{S}_{(\mathrm{i}+1, \mathrm{j}+1)}=(\mathrm{r}, \theta \pm \pi)$.

4- $\quad S_{(i, j+1)}=(r, \theta \pm \pi)=\left(r, \theta_{2}\right) \operatorname{AndS}_{(i+1, j)}=(r, \theta \pm \pi)=\left(r, \theta_{2} \pm \pi / 2\right)$.

5- $\quad \mathrm{S} * \mathrm{~S}^{* \mathrm{~T}}=\mathrm{K} * \mathrm{I}$ Where $\mathrm{I}$ is identity matrix with $n \times n$ dimensions and $\mathrm{k}$ is any number but can be calculate.

6- This is important $\sum_{i=1}^{n} \sum_{j=1}^{n} \mathrm{~S}_{(\mathrm{i}, \mathrm{j})}=$ zreo .

The following test can be applied to the $4 x 4$ FFT matrix to prove that it is not fully orthogonal:

I-The columns: Take any column and multiply it by the conjugate of any other column, as illustrated below:

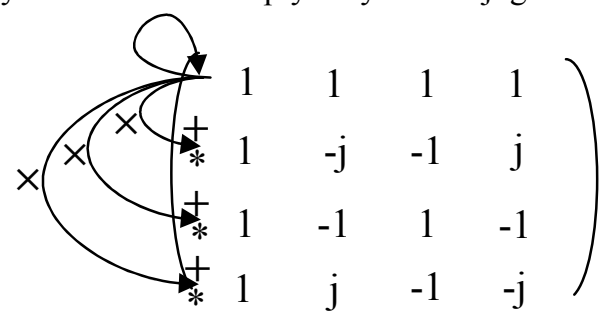

$\mathbf{C}_{\mathrm{n}} \times \mathbf{C}_{\mathrm{m}}^{*}=\left\{\begin{array}{l}0 \text { if } \mathrm{n} \neq \mathrm{m} \\ \mathrm{k} \text { if } \mathrm{n}=\mathrm{m}\end{array}\right.$

$\mathbf{R}_{\mathrm{n}} \times \mathbf{R}_{\mathrm{m}}^{*}=\left\{\begin{array}{l}0 \text { if } \mathrm{n} \neq \mathrm{m} \\ \mathrm{k} \text { if } \mathrm{n}=\mathrm{m}\end{array}\right.$

Where $\mathbf{C}$ is the Column and $\mathrm{R}$ the row of the any matrix (in this case square matrix): 


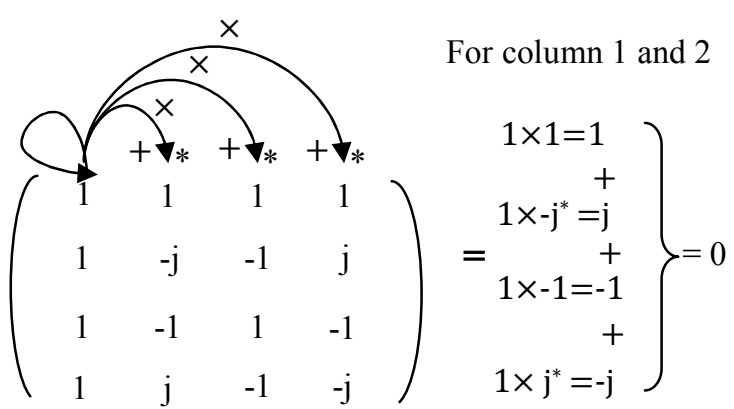

$$
\left.\begin{array}{r}
\left.\begin{array}{r}
1 \times 1=1 \\
+ \\
1 \times-1=-1 \\
+ \\
1 \times 1=1 \\
+ \\
1 \times-1=-1
\end{array}\right\}=0 \\
1 \times-1=-1 \\
+ \\
+j^{*}=-j \\
1 \times-j^{*}=j
\end{array}\right\}=0
$$

The final result can be summarized as ( $\left(\begin{array}{llll}4 & 0 & 0 & 0\end{array}\right)$, where the dot stands for the first column, the zeros for the others. For the second column ( $\left.\begin{array}{llll}0 & 4 & 0 & 0\end{array}\right)$, for the third column $\left(\begin{array}{llll}0 & 0 & 4 & 0\end{array}\right)$, for the forth column $\left(\begin{array}{llll}0 & 4 & 0\end{array}\right)$,

II-And so on for the rows Elements by elements if we take $2 \times 2$ FFT matrix (= Hadamard matrix) $\left[\begin{array}{rr}1 & 1 \\ 1 & -1\end{array}\right]$ then:

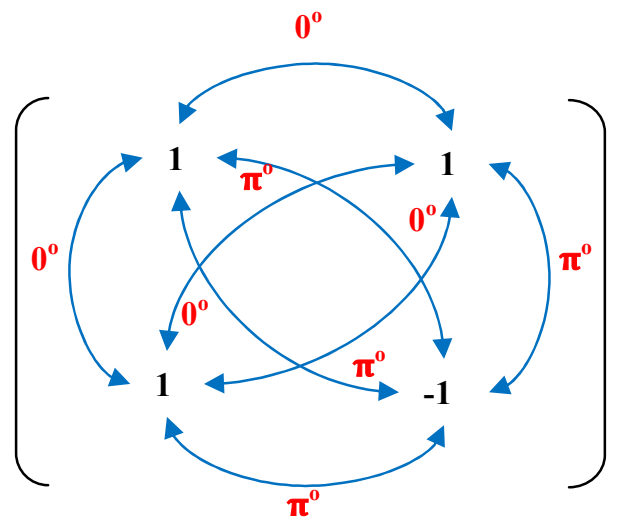

Figure 1. Phases between points in 2DFFT matrix

\section{Generation of Basic Matrix}

So the basic matrix and all matrix (can seen in $4 \times 4$ FFT matrix) not orthogonal elements by elements. We must find basic matrix with all condition and: 
International Journal of

Soft Computing And Software Engineering (JSCSE)

e-ISSN: 2251-7545

Vol.2,No.6, 2012

Published online: Jun 17, 2012

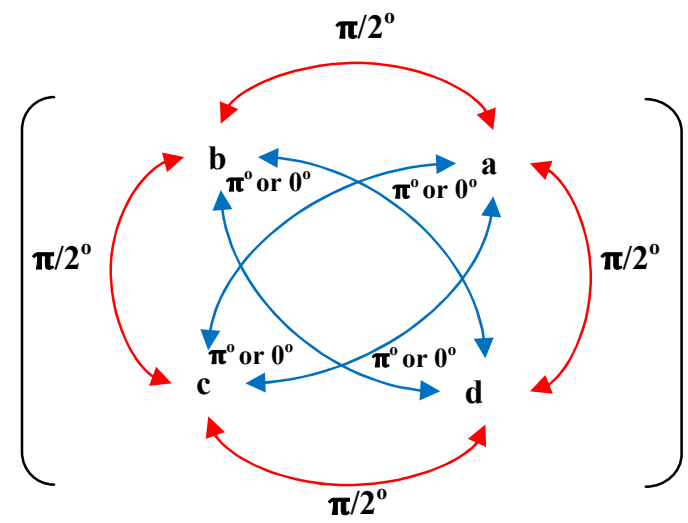

Figure 2. Phases between points in basic matrix

Or all elements:

$1-S_{(i, j)}=(r, \theta)$, there are $S_{(i+1, j)}=\left(r, \theta \pm \frac{\pi}{2}\right)$ and $S_{(i, j+1)}=(r, \theta \pm \pi / 2)$.

2- $\mathrm{S}_{(\mathrm{i}+1, \mathrm{j}+1)}=(\mathrm{r}, \theta \pm \pi)$.

3- $\mathbb{S} * \mathbb{S}^{* T}=\mathrm{K} * \mathrm{I}$ Where I is identity matrix with $\mathrm{n} \times \mathrm{n}$.

It can be provided that from QAM and QPSK as shown below in Fig-1-.

So the basic matrix is given by:

$\mathrm{a}=1$ or $1+\mathrm{j}$

$\mathrm{b}=\mathrm{j}$ or $-1+\mathrm{j}$

$\mathrm{c}=-1$ or $-1-\mathrm{j}$

$\mathrm{d}=-\mathrm{j}$ or $1-\mathrm{j}$ 
International Journal of

Soft Computing And Software Engineering (JSCSE)

e-ISSN: 2251-7545

Vol.2,No.6, 2012

Published online: Jun 17, 2012
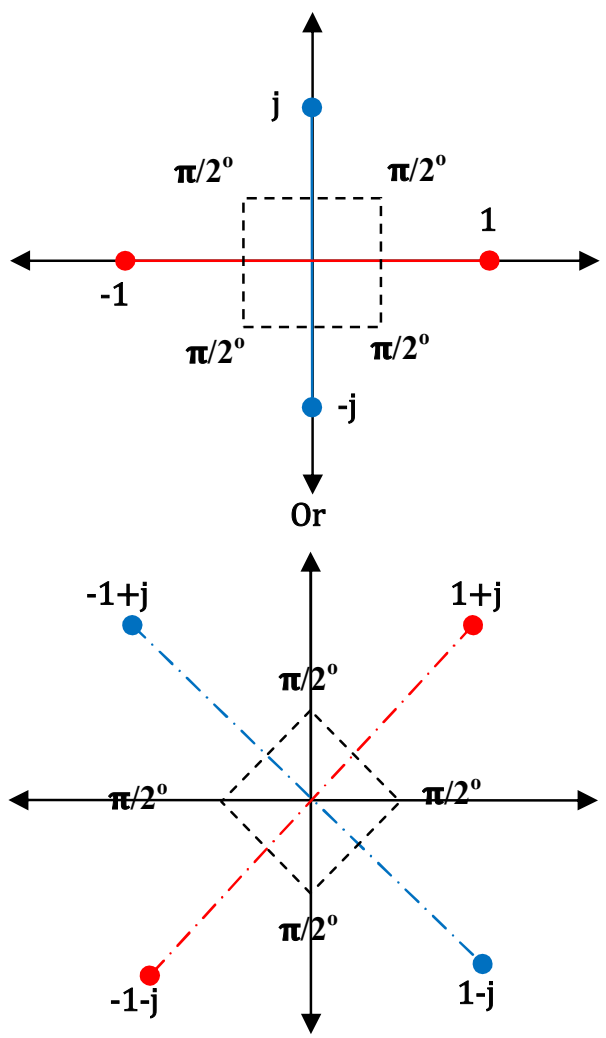

Figure 3. Points in 4QAM

Then basic matrix will be for example as:

$$
\left(\begin{array}{cc}
\mathrm{j} & 1 \\
-1 & -\mathrm{j}
\end{array}\right) \text { OR }\left(\begin{array}{cc}
-1+\mathrm{j} & 1+\mathrm{j} \\
-1-\mathrm{j} & 1-\mathrm{j}
\end{array}\right)
$$

And we can cyclic they as shown in example:

$$
\begin{aligned}
& \left(\begin{array}{rr}
-\mathrm{j} & 1 \\
-1 & \mathrm{j}
\end{array}\right),\left(\begin{array}{rr}
1 & \mathrm{j} \\
-\mathrm{j} & -1
\end{array}\right),\left(\begin{array}{rr}
-1 & -\mathrm{j} \\
\mathrm{j} & 1
\end{array}\right) \text { or } \\
& \left(\begin{array}{rr}
1+\mathrm{j} & 1-\mathrm{j} \\
-1+\mathrm{j} & -1-\mathrm{j}
\end{array}\right) \text { And so on. }
\end{aligned}
$$

For $100 \%$ orthogonal we must find every rows and columns multiply as shown in equations 4 and 4.1 or will be equal to zero, and for element by element the basics matrices are orthogonal for all elements. So it is orthogonal basic matrix for all rows columns and elements by elements, now for $4 \times 4$ matrix it can use Hadamard matrix as a tenser product as given in Fig.4 and:

$\mathbb{S}_{4 \times 4}=H_{2 \times 2} \otimes \mathbb{S}_{2 \times 2}=\left(\begin{array}{cc}1 & 1 \\ 1 & -1\end{array}\right) \otimes\left(\begin{array}{cc}j & 1 \\ -1 & -j\end{array}\right)=\left(\begin{array}{rrrr}j & 1 & j & 1 \\ -1 & -j & -1 & -j \\ j & 1 & -j & -1 \\ -1 & -j & 1 & j\end{array}\right)$

Then make the three tests to the $\mathrm{S}_{4 \times 4}$ then we find: 
International Journal of

Soft Computing And Software Engineering (JSCSE)

e-ISSN: 2251-7545

Vol.2,No.6, 2012

Published online: Jun 17, 2012

DOI: 10.7321/jscse.v2.n6.5

1-Element by elements:

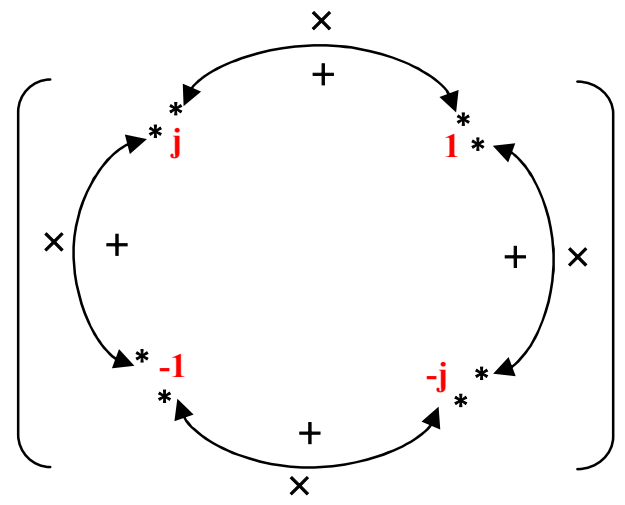

Figure 4. Applied equations 4 and 4.1

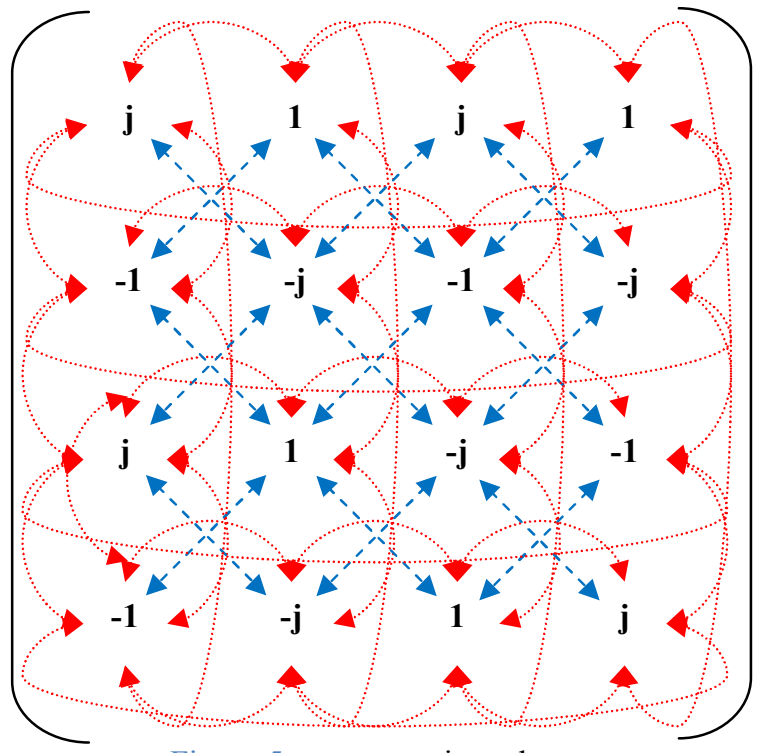

Figure 5.tenser matrix and tests

Where the slant line (The dotted and red line) represents a $90^{\circ}(\pi / 2)$ degree angle and the straight line (intersecting and blue) represents a $180^{\circ}(\pi)$ degree angle and we find:

a) $\mathrm{S}_{(\mathrm{i}, \mathrm{j})}=(\mathrm{r}, \theta)$ then every $\mathrm{S}_{(\mathrm{i}+1, \mathrm{j})}=\left(\mathrm{r}, \theta \pm 90^{\circ}\right)$.

b) $\mathrm{S}_{(\mathrm{i}, \mathrm{j}}=(\mathrm{r}, \theta)$ then every $\mathrm{S}_{(\mathrm{i}, \mathrm{j}+1)}=\left(\mathrm{r}, \theta \pm 90^{\circ}\right)$.

c) $\mathrm{S}_{(\mathrm{i}, \mathrm{j})}=(\mathrm{r}, \theta)$ then every $\mathrm{S}_{(\mathrm{i}+1, \mathrm{j})}=\left(\mathrm{r}, \theta \pm 90^{\circ}\right)=\left(\mathrm{r}, \theta_{2}\right)$ then $\mathrm{S}_{(\mathrm{i}, \mathrm{j}+1)}=\left(\mathrm{r}, \theta_{2} \pm 180^{\circ}\right)$ or $\mathrm{S}_{(\mathrm{ij}+1)}=\left(\mathrm{r}, \theta_{2}+0^{\circ}\right)$

d) $\mathrm{S}_{(\mathrm{i}, \mathrm{j})}=(\mathrm{r}, \theta)$ then every $\mathrm{S}_{(\mathrm{i}+1, \mathrm{j}+1)}=\left(\mathrm{r}, \theta \pm 180^{\circ}\right)$ or $\mathrm{S}_{(\mathrm{i}+1, \mathrm{j}+1)}=\left(\mathrm{r}, \theta+0^{\circ}\right)$.

Where $\mathrm{i}=\mathrm{j}(\mathrm{j}$ here is not $\sqrt{-1})$. And for $\mathbb{S}_{2 \times 2}$ shifted by $45^{\circ}$ or $\pi / 4$ then:

$\pi_{\pi / 4} \mathbb{S}_{2 \times 2}=\left(\begin{array}{ll}-1+\mathrm{j} & 1+\mathrm{j} \\ -1-\mathrm{j} & 1-\mathrm{j}\end{array}\right)$ And $_{\pi / 4} \mathbb{S}_{4 \times 4}$ using Hadamard matrix: 


$$
\begin{aligned}
& \pi_{\pi / 4} \mathbb{S}_{4 \times 4}=\mathrm{H}_{2 \times 2} \bigotimes_{\pi / 4} \mathbb{S}_{2 \times 2}=\left(\begin{array}{cc}
1 & 1 \\
1 & -1
\end{array}\right) \otimes\left(\begin{array}{cc}
-1+\mathrm{j} & 1+\mathrm{j} \\
-1-\mathrm{j} & 1-\mathrm{j}
\end{array}\right) \\
& \pi / 4 \mathbb{S}_{4 \times 4}=\left(\begin{array}{rrrr}
-1+j & 1+j & -1+j & 1+j \\
-1-j & 1-j & -1-j & 1-j \\
-1+j & 1+j & 1-j & -1-j \\
-1-j & 1-j & 1+j & -1+j
\end{array}\right)
\end{aligned}
$$

And we must find:

e) $\pi / 4 \mathrm{~S}_{(\mathrm{i}, \mathrm{j})}=\left(\mathrm{r}, \theta+45^{0}\right)=\left(\mathrm{r}, \theta^{\#}\right)$, then every ${ }_{\pi / 4} \mathrm{~S}_{(\mathrm{i}+1, \mathrm{j})}=\left(\mathrm{r}, \theta^{\#} \pm 90^{0}\right)$.

f) $\pi / 4 S_{(i, j)}=\left(r, \theta^{\#}\right)$, then every ${ }_{\pi / 4} S_{(i, j+1)}=\left(r, \theta^{\#} \pm 90^{0}\right)$.

g) $\pi / 4 S_{(i, j)}=\left(r, \theta^{\#}\right)$, then every $\pi_{\pi / 4} S_{(i, j+1)}=\left(r, \theta^{\#} \pm 90^{0}\right)=\left(r, \theta_{2}^{\#}\right) \cdot$ then $S_{(i, j+1)}=\left(r, \theta_{2}^{\#} \pm 180^{\circ}\right)$ or $\mathrm{S}_{(\mathrm{i}, \mathrm{j}+1)}=\left(\mathrm{r}, \theta_{2}+0^{\circ}\right)$

h) $\mathrm{S}_{(\mathrm{i}, \mathrm{j})}=(\mathrm{r}, \theta)$ then every $\mathrm{S}_{(\mathrm{i}+1, \mathrm{j}+1)}=\left(\mathrm{r}, \theta \pm 180^{\circ}\right)$ or $\mathrm{S}_{(\mathrm{i}+1, \mathrm{j}+1)}=\left(\mathrm{r}, \theta+0^{\circ}\right)$.
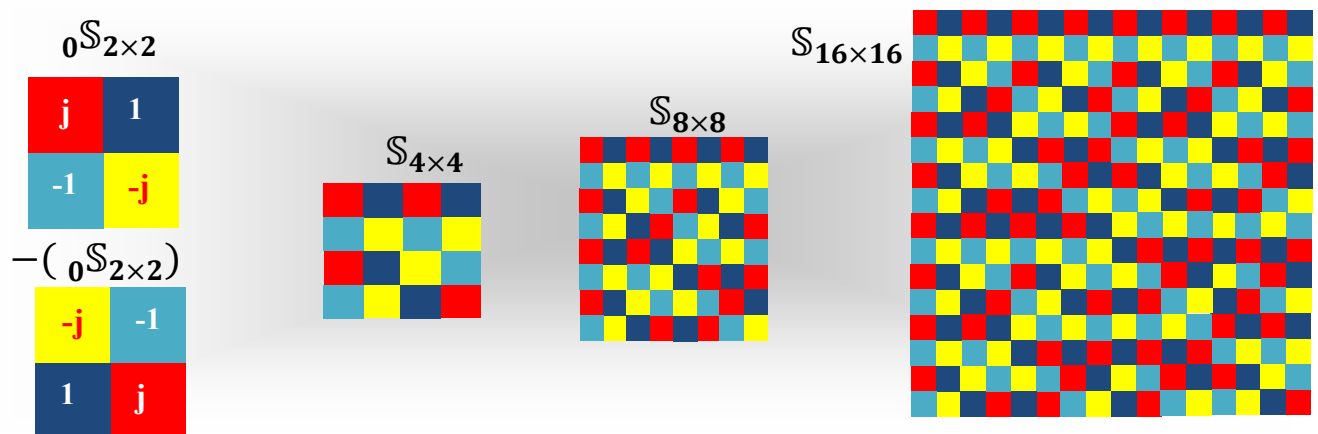

Figure 6. Representations $\mathbb{S}_{\mathrm{nxn}}$ by color.

2-For all columns: 
Published online: Jun 17, 2012

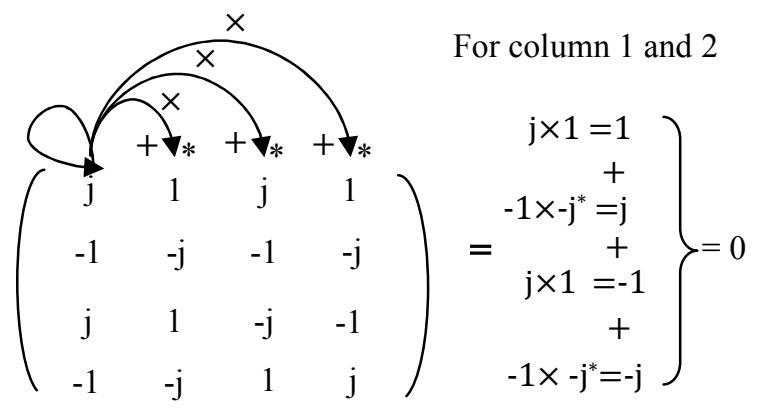

For column 1 and $3 \quad$ For column 1 and 4

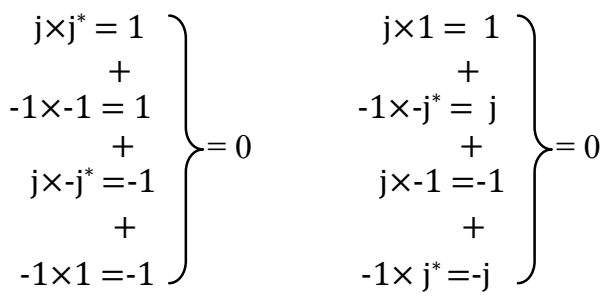

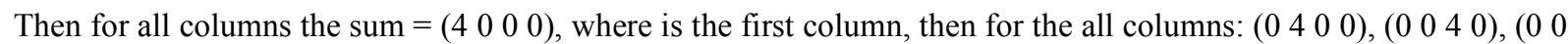
$04)$.

3-For all rows:

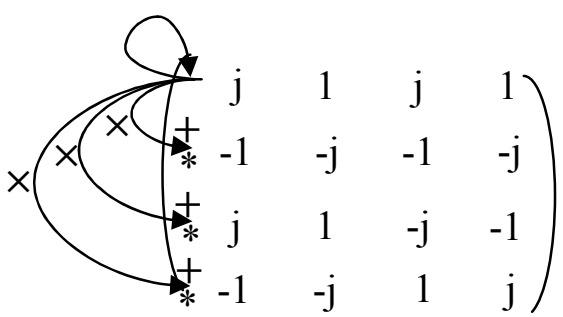

Or:

$$
\begin{aligned}
\mathbb{S}_{2 \times 2} * \mathbb{S}_{2 \times 2}^{* \mathrm{~T}}= & \left(\begin{array}{cc}
\mathrm{j} & 1 \\
-1 & -\mathrm{j}
\end{array}\right) *\left(\begin{array}{cc}
\mathrm{j} & -1 \\
1 & -\mathrm{j}
\end{array}\right)^{* \mathrm{~T}}=\left(\begin{array}{cc}
\mathrm{j} & 1 \\
-1 & -\mathrm{j}
\end{array}\right) *\left(\begin{array}{cc}
\mathrm{j} & -1 \\
1 & -\mathrm{j}
\end{array}\right)^{*}=\left(\begin{array}{cc}
\mathrm{i} & 1 \\
-1 & -\mathrm{i}
\end{array}\right) *\left(\begin{array}{cc}
-\mathrm{i} & -1 \\
1 & \mathrm{i}
\end{array}\right)=\left(\begin{array}{cc}
2 & 0 \\
0 & 2
\end{array}\right) \\
& =2\left(\begin{array}{cc}
1 & 0 \\
0 & 1
\end{array}\right)=2 * \mathrm{I}
\end{aligned}
$$

And:

$\frac{\pi}{4} \mathbb{S}_{2 \times 2} * \frac{\pi}{4} \mathbb{S}_{2 \times 2}^{* \mathrm{~T}}=$

$$
\left(\begin{array}{ll}
-1+\mathrm{j} & 1+\mathrm{j} \\
-1-\mathrm{j} & 1-\mathrm{j}
\end{array}\right) *\left(\begin{array}{ll}
-1+\mathrm{j} & 1+\mathrm{j} \\
-1-\mathrm{j} & 1-\mathrm{j}
\end{array}\right)^{* \mathrm{~T}}=\left(\begin{array}{ll}
4 & 0 \\
0 & 4
\end{array}\right)=4\left(\begin{array}{ll}
1 & 0 \\
0 & 1
\end{array}\right)=4 * \mathrm{I}
$$

${ }_{0} \mathbb{S}_{4 \times 4} *{ }_{0} \mathbb{S}_{4 \times 4}^{* \mathrm{~T}}=4 * \mathrm{I}$.

$\pi / 4 \mathbb{S}_{4 \times 4} *{ }_{45^{\circ}} \mathbb{S}_{4 \times 4}^{* \mathrm{~T}}=8 * \mathrm{I}$

Or from equation 6 and 7 
International Journal of

Soft Computing And Software Engineering (JSCSE)

e-ISSN: 2251-7545

Vol.2,No.6, 2012

Published online: Jun 17, 2012

$\mathbb{S}_{\mathrm{n} \times \mathrm{n}} * \mathbb{S}_{\mathrm{n} \times \mathrm{n}}^{* \mathrm{~T}}=\mathrm{n} * \mathrm{I}$

$\frac{\pi}{4} \mathbb{S}_{\mathrm{n} \times \mathrm{n}} * \frac{\pi}{4} \mathbb{S}_{\mathrm{n} \times \mathrm{n}}^{* \mathrm{~T}}=2 \mathrm{n} * \mathrm{I}$

, (if $r=\sqrt{2}$ )

And we can make unlimited basic matrix as shown, like the figure below:

$\theta^{o} \mathbb{S}_{2 \times 2}=\left(\begin{array}{cc}r \cos \left(\theta^{\circ}+\frac{\pi}{2}\right)+j \sin \left(\theta^{\circ}+\frac{\pi}{2}\right) & r \cos \left(\theta^{\circ}\right)+j r \sin \left(\theta^{\circ}\right) \\ r \cos \left(\theta^{\circ}+\pi\right)+j \sin \left(\theta^{\circ}+\pi\right) & r \cos \left(\theta^{\circ}-\frac{\pi}{2}\right)+j r \sin \left(\theta^{\circ}-\frac{\pi}{2}\right)\end{array}\right)$

If not $\pi / 2$ phase shift then the equation will be:

$\left(S_{n}\right)^{p}=\left(\begin{array}{c}r \cos \left(\theta^{o}+\beta^{o}+\frac{2 \pi}{\mathrm{n}}\right) \\ +\mathrm{j} \operatorname{rsin}\left(\theta^{o}+\beta^{o}+\frac{2 \pi}{\mathrm{n}}\right)\end{array}\right)^{\mathrm{p}}$

Where: $n=$ number of consolation points $\mathrm{n}>0 \mathrm{p}=$ power $\theta^{\circ}=$ phase shift $\beta^{\circ}=$ phase start for $\mathrm{r}=1, \mathrm{n}=4$, $\theta^{\circ}=0^{\circ}$ and $\beta^{\circ}=0^{\circ} \quad S_{n}=1,-1, i-i$

Then make a tenser with:

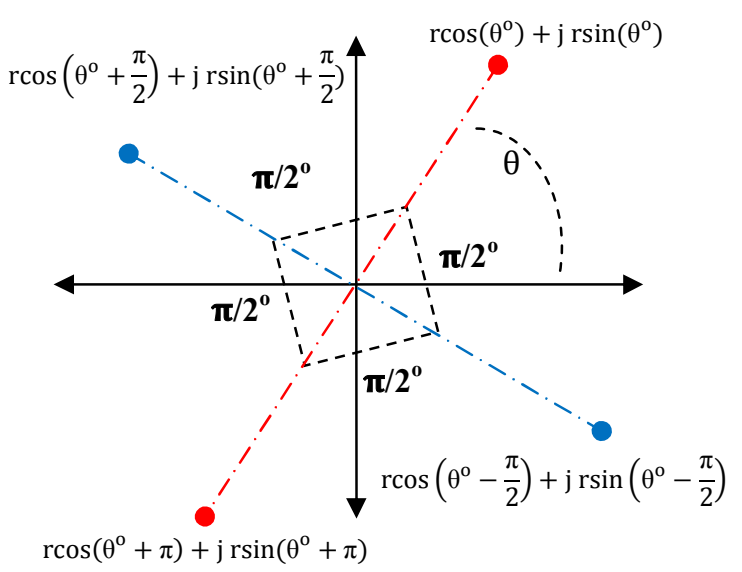

Figure 7. Constellation Points for 4QAM and shifted by $\theta$.

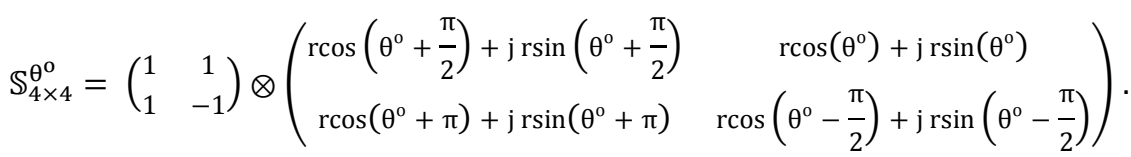

And so on: 
International Journal of

Soft Computing And Software Engineering (JSCSE)

e-ISSN: 2251-7545

Vol.2,No.6, 2012

Published online: Jun 17, 2012

$\left(\begin{array}{cc}1 & 1 \\ 1 & -1\end{array}\right) \otimes \mathbb{S}_{4 \times 4}^{\theta^{\mathrm{o}}}=\mathbb{S}_{8 \times 8}^{\theta^{\mathrm{o}}} \quad$ or : $\left(\begin{array}{cc}1 & 1 \\ 1 & -1\end{array}\right) \otimes \mathbb{S}_{\mathrm{n} \times \mathrm{n}}^{\theta^{\mathrm{o}}}=\mathbb{S}_{2 \mathrm{n} \times 2}^{\theta^{\mathrm{o}}}$

\section{Euler form}

So for last equation we can use Euler method with $r=1$ to representation the matrix in form:

$e^{j \theta}=\cos \theta+j \sin \theta$

And:

$$
{ }_{\theta} \mathbb{S}_{\text {or }}^{p}=\left(e^{j\left(\theta+\left(\text { or } * \frac{\pi}{2}\right)\right)}\right)^{p}=\left(\cos \left(\theta+\left(\text { or } * \frac{\pi}{2}\right)\right)+j \sin \left(\theta+\left(\text { or } * \frac{\pi}{2}\right)\right)\right)^{p}
$$

Where or $=0,1,2$ and 3 , and $p=1,2,3 \ldots$

$S_{0}=e^{j \theta}={ }_{\theta} S_{0}^{1}=S, S_{1}=e^{j\left(\theta+\frac{\pi}{2}\right)}={ }_{\theta} S_{\frac{\pi}{2}}, S_{2}=e^{j(\theta+\pi)}={ }_{\theta} S_{\pi}$,

And $S_{3}=e^{j\left(\theta-\frac{\pi}{2}\right)}={ }_{\theta} S_{-\frac{\pi}{2}}$ if $\theta=0^{\circ}$ then:

$\mathbb{S}_{2 \times 2}=\left(\begin{array}{ll}S_{1} & S_{0} \\ S_{2} & S_{3}\end{array}\right)=\left(\begin{array}{cc}S_{\frac{\pi}{2}} & S \\ S_{\pi} & S_{-\frac{\pi}{2}}\end{array}\right)$

Now for expansion we can make Hadamard matrix in the fallowing form:

a) $\mathbb{S}_{4 \times 4}=\left(\begin{array}{cc}S & S \\ S & S_{\pi}\end{array}\right) \otimes\left(\begin{array}{cc}{ }_{\theta} S_{\frac{\pi}{2}} & { }_{\theta} S_{0} \\ { }_{\theta} S_{\pi} & { }_{\theta} S_{-\frac{\pi}{2}}\end{array}\right)$ or

$\mathbb{S}_{4 \times 4}=\left(\begin{array}{cc}\mathbb{S}_{2 \times 2} & \mathbb{S}_{2 \times 2} \\ \mathbb{S}_{2 \times 2} & \mathbb{S}_{2 \times 2}{ }^{-1}\end{array}\right)$ if and only if $\mathbb{S}_{2 \times 2}{ }^{-1}=-\mathbb{S}_{2 \times 2}$

A square matrix with complex number is said skew-Hermitian if the conjugate transpose for it was equal to its negative.

$$
\text { b) } \mathbb{S}_{4 \times 4}=\left(\begin{array}{cc}
S_{\frac{\pi}{2}} & S_{\frac{\pi}{2}} \\
S_{\frac{\pi}{2}} & S_{-\frac{\pi}{2}}
\end{array}\right) \otimes\left(\begin{array}{cc}
{ }_{\theta} S_{\frac{\pi}{2}} & { }_{\theta} S_{0} \\
{ }_{\theta} S_{\pi} & { }_{\theta} S_{-\frac{\pi}{2}}
\end{array}\right)
$$

1- For a) $S * S=e^{j \theta} * e^{j \theta}$,

If we rewrite with $\theta=0^{\circ}$ then the formal will be:

For b) $S * S_{\frac{\pi}{2}}=e^{j \theta} * e^{j\left(\theta+\frac{\pi}{2}\right)}=e^{j 2 \theta} * e^{j \frac{\pi}{2}}$

$$
S * S=e^{j \theta} * e^{j \theta}={ }_{0} S_{0}^{2}=S^{2}
$$

If we rewrite $e^{j \frac{\pi}{2}}=S_{1}$ with $\theta=0^{\circ}$ then the formal will be:

$$
S * S_{\frac{\pi}{2}}=e^{j \theta} * e^{j\left(\theta+\frac{\pi}{2}\right)}=e^{j 2 \theta} * e^{j \frac{\pi}{2}}=S^{2} * e^{j \frac{\pi}{2}}=S^{2} *{ }_{0} S_{1}
$$

2- For a) $S * S_{\pi}=e^{j \theta} * e^{j(\theta+\pi)}=e^{j 2 \theta} * e^{j \pi}$

If we rewrite $e^{j \pi}=S_{2}$ or $S_{\pi}$ with $\theta=0^{\circ}$ then the formal will be:

$$
S * S_{\pi}=S_{0}^{2} S_{\pi}
$$


International Journal of

Soft Computing And Software Engineering (JSCSE)

e-ISSN: 2251-7545

Vol.2,No.6, 2012

Published online: Jun 17, 2012

DOI: 10.7321/jscse.v2.n6.5

For b) $S * S_{-\frac{\pi}{2}}=e^{j \theta} * e^{j\left(\theta-\frac{\pi}{2}\right)}=e^{j 2 \theta} * e^{-j \frac{\pi}{2}}=S^{2} S_{-\frac{\pi}{2}}$

If we rewrite $e^{-j \frac{\pi}{2}}=S_{3}$ or ${ }_{0} S_{-\frac{\pi}{2}}$ with $\theta=0^{\circ}$ then the formal will be:

$$
S * S_{-\frac{\pi}{2}}=S^{2}{ }_{0} S_{-\frac{\pi}{2}}
$$

Then the matrix $\mathbb{S}_{4 \times 4}$ with $\theta=0^{\circ}$ then the formal will be:

$$
\begin{gathered}
\mathbb{S}_{4 \times 4}=\left(\begin{array}{cccccc}
{ }_{0} S_{0}^{2} * & { }_{0} S_{1} & { }_{0} S_{0}^{2} & { }_{0} S_{0}^{2} *{ }_{0} S_{1} & { }_{0} S_{0}^{2} \\
{ }_{0} S_{0}^{2} * & { }_{0} S_{2} & { }_{0} S_{0}^{2} *{ }_{0} S_{3} & { }_{0} S_{0}^{2} * & { }_{0} S_{2} & { }_{0} S_{0}^{2} *{ }_{0} S_{3} \\
{ }_{0} S_{0}^{2} * & { }_{0} S_{1} & { }_{0} S_{0}^{2} & { }_{0} S_{0}^{2} * & { }_{0} S_{3} & { }_{0} S_{0}^{2} *{ }_{0} S_{2} \\
{ }_{0} S_{0}^{2} * & { }_{0} S_{2} & { }_{0} S_{0}^{2} *{ }_{0} S_{3} & { }_{0} S_{0}^{2} & { }_{0} S_{0}^{2} *{ }_{0} S_{1}
\end{array}\right)={ }_{0} S_{0}^{2} *\left(\begin{array}{ccccc}
{ }_{0} S_{1} & 1 & { }_{0} S_{1} & 1 \\
{ }_{0} S_{2} & { }_{0} S_{3} & { }_{0} S_{2} & { }_{0} S_{3} \\
{ }_{0} S_{1} & 1 & { }_{0} S_{3} & { }_{0} S_{2} \\
{ }_{0} S_{2} & { }_{0} S_{3} & 1 & { }_{0} S_{1}
\end{array}\right) \\
={ }_{0} S_{0}^{2} *\left(\begin{array}{rrrrr}
\mathrm{j} & 1 & \mathrm{j} & 1 \\
-1 & -\mathrm{j} & -1 & -\mathrm{j} \\
\mathrm{j} & 1 & -\mathrm{j} & -1 \\
-1 & -\mathrm{j} & 1 & \mathrm{j}
\end{array}\right)
\end{gathered}
$$

\begin{tabular}{|c|c|c|c|}
\hline $\begin{array}{c}\theta=0 \\
\text { and } o r=0,1,2 \text { and } 3 \\
\end{array}$ & number & $\begin{array}{c}\theta=\pi \\
\text { and } o r=0,1,2 \text { and } 3\end{array}$ & number \\
\hline${ }_{0} \mathrm{~S}_{0}$ & 1 & ${ }_{\pi} \mathbf{S}_{0}$ & -1 \\
\hline${ }_{0} \mathrm{~S}_{1}$ & $\mathbf{j}$ & ${ }_{\pi} \mathrm{S}_{1}$ & $-\mathbf{j}$ \\
\hline${ }_{0} \mathrm{~S}_{2}$ & -1 & ${ }_{\pi} \mathbf{S}_{2}$ & 1 \\
\hline${ }_{0} \mathrm{~S}_{3}$ & $-\mathbf{j}$ & ${ }_{\pi} \mathrm{S}_{3}$ & $\mathbf{j}$ \\
\hline $\begin{array}{c}\theta=\pi / 2 \\
\text { and } o r=0,1,2 \text { and } 3\end{array}$ & number & $\begin{array}{c}\theta=-\pi / 2 \\
\text { and } 0 r=0,1,2 \text { and } 3\end{array}$ & number \\
\hline$\pi / 2 S_{0}$ & $\mathbf{j}$ & $-\pi / 2 S_{0}$ & $-\mathbf{j}$ \\
\hline$\pi / 2 S_{1}$ & -1 & $-\pi / 2 \mathrm{~S}_{1}$ & 1 \\
\hline$\pi / 2 \mathbf{S}_{2}$ & $-\mathbf{j}$ & $-\pi / 2 \mathbf{S}_{2}$ & $\mathbf{j}$ \\
\hline$\pi / 2 \mathrm{~S}_{3}$ & 1 & $-\pi / 2 S_{3}$ & -1 \\
\hline
\end{tabular}

Table 1. The number S.

\section{Application}

In this section will introduce the application and compare with FFT matrix, the application consist the communication and DSP. The communication will be the digital transmitter like OFDM and the DSP using the basic matrix as filter, the both system will be have resulting and compare with the original system in the power and performance.

\section{OFDM System}

Orthogonal Frequency Division Multiplexing (OFDM) is similar to used technique of Frequency Division Multiplexing (FDM). But it is allow multiple messages to be sent over a single channel. It is allowing an improved spectral efficiency. The Fourier transform (or other transform) data communication system is a realization of FDM in which discrete Fourier transform are computed as part of modulation and demodulation process. In addition to a completely digital implementation can be built around a special-purpose computer performing the fast Fourier transform $[5,6,7,8]$. OFDM has recently been applied widely in wireless communication systems due to its high data rate transmission 
International Journal of

Soft Computing And Software Engineering (JSCSE)

e-ISSN: 2251-7545

Vol.2,No.6, 2012

Published online: Jun 17, 2012

capability with high bandwidth efficiency and its robustness to multi-path delay. It has been used in wireless standards such as IEEE802.11a and the equivalent HIPERLAN/2 and in multimedia wireless services such as Multimedia Mobile Access Communications. A dynamic estimation of channel is necessary before the demodulation of OFDM signals since the radio channel is frequency selective and time-varying for wideband mobile communication systems $[5,6,7,8]$. The block diagram of the given system for OFDM is depicted in Fig.8. The OFDM modulator and demodulator of FFT-based OFDM is shown in Fig.9.

First of all, the input serial data stream is formatted into the word size required for transmission e.g. 2 bit/word for QPSK and 4 bit/word for 16-QAM, and shift into a parallel format. The data is then transmitted in parallel by assigning each word to one sub-carrier in the transmission. After that, the data to be transmitted on each sub-carrier is then mapped into QPSK or 16- QAM constellation format. This process will convert data to corresponding value of M-ary constellation which is complex word, i.e. real and imaginary part. The training frame (pilot sub-carriers frame) will be inserted and sent prior to information frame. This pilot frame will be used for channel estimation that's used to compensate the channel effects on the signal. After that, the complex words frame and pilots frame will pass to IFFT to generate an OFDM symbol. Zeros will be inserted in some bins of the IFFT in order to make the transmitted spectrum compacts and reduce the adjacent carrier's interference.

Now if we can replace the FFT and IFFT for (n) length data by the $\mathbb{S}_{n \boldsymbol{n} \boldsymbol{n}}$ matrix and study the performance in the following condition in table -2-

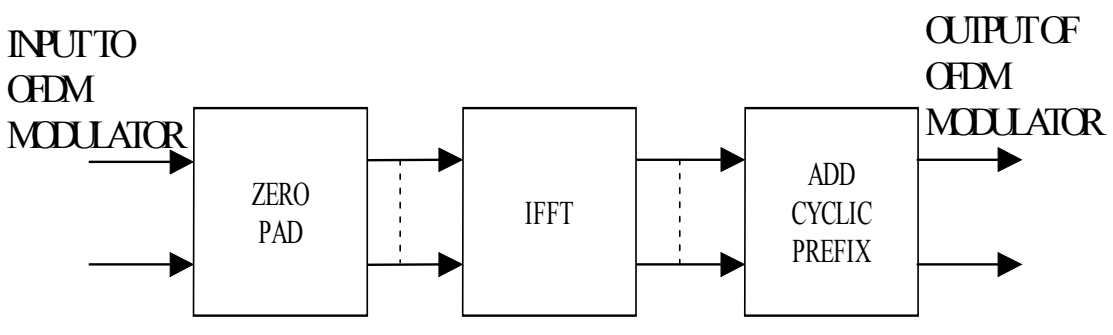

a- OFDM Modulator

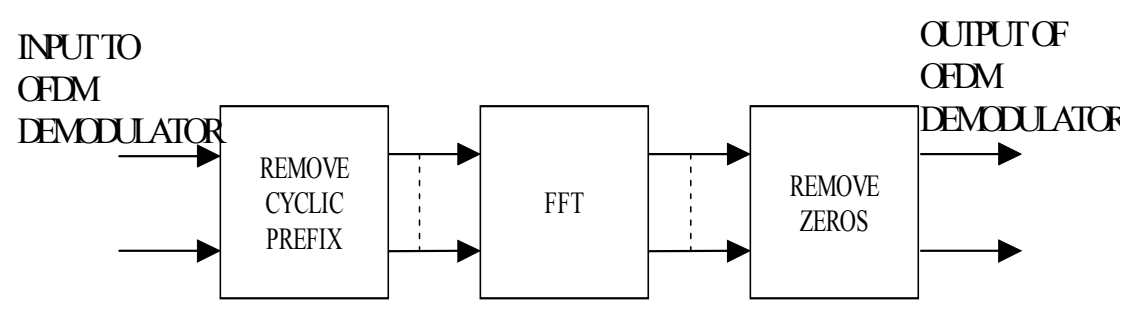

b-OFDM Demodulator

Figure 8.The OFDM modem system. 
International Journal of

Soft Computing And Software Engineering (JSCSE)

e-ISSN: 2251-7545

Vol.2,No.6, 2012

Published online: Jun 17, 2012

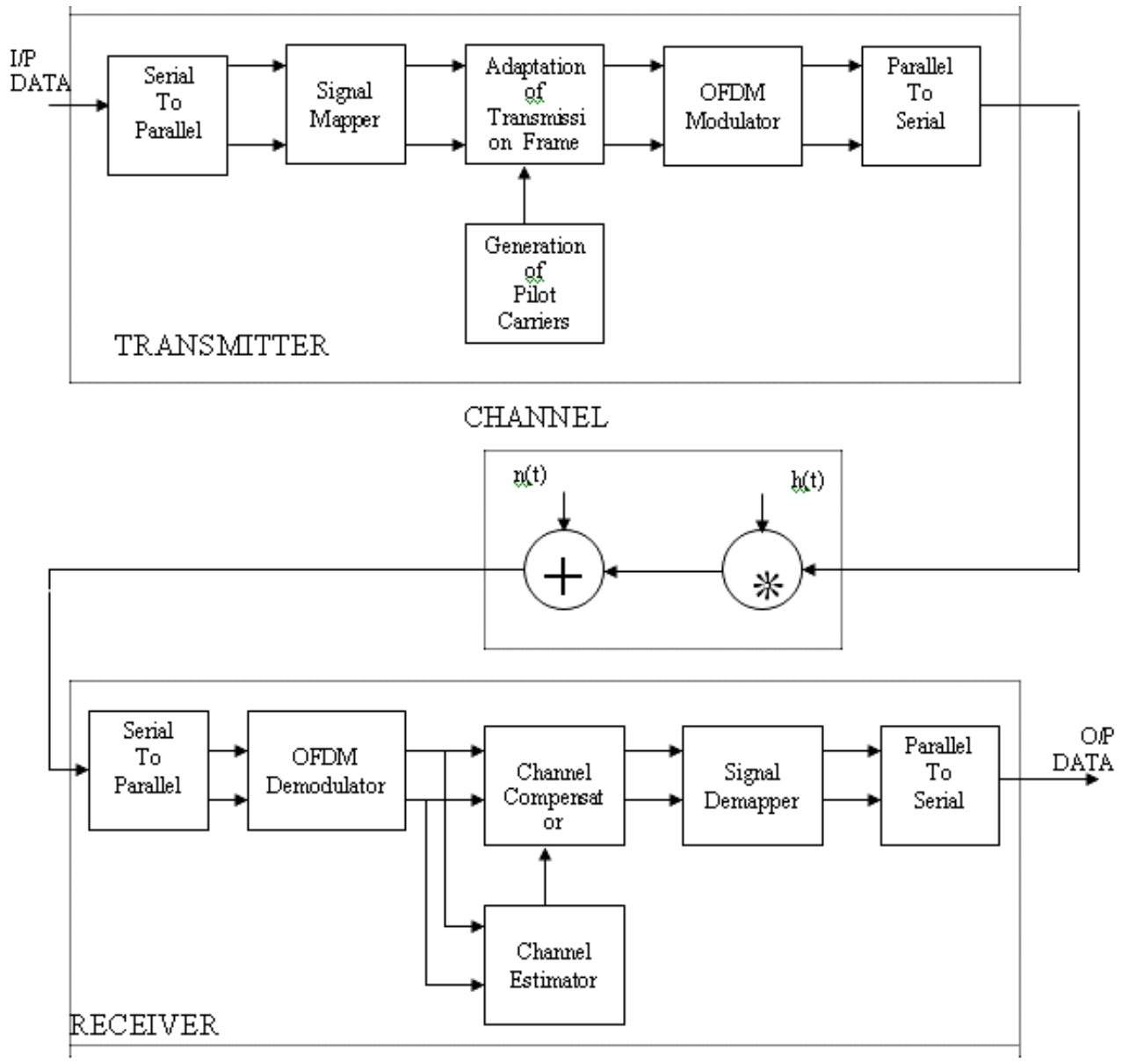

Figure 9.Block Diagram of OFDM System.

Table 2.The conditions.

\begin{tabular}{|c||c||}
\hline Modulation Types & 4Q \& 16QAM \\
\hline \hline Number of sub-carriers & 64 or 32 sub-carriers \\
\hline Number of FFT points & 64 or 32 FFT points \\
\hline \hline Damnation of $\mathbb{S}_{\mathrm{nn}}$ & $64 \times 64$ or 32x32 \\
\hline \hline Channel model & Flat fading + AWGN \\
\hline
\end{tabular}


International Journal of

Soft Computing And Software Engineering (JSCSE)

e-ISSN: 2251-7545

Vol.2,No.6, 2012

Published online: Jun 17, 2012

\begin{tabular}{|c||c|}
\hline & $\begin{array}{c}\text { Frequency selective } \\
\text { fading + AWGN }\end{array}$ \\
\hline \hline Doublers Shifts & $50 \mathrm{~Hz}$ \\
\hline SNR & Maximum 60 dB \\
\hline
\end{tabular}

The resulting shown below:

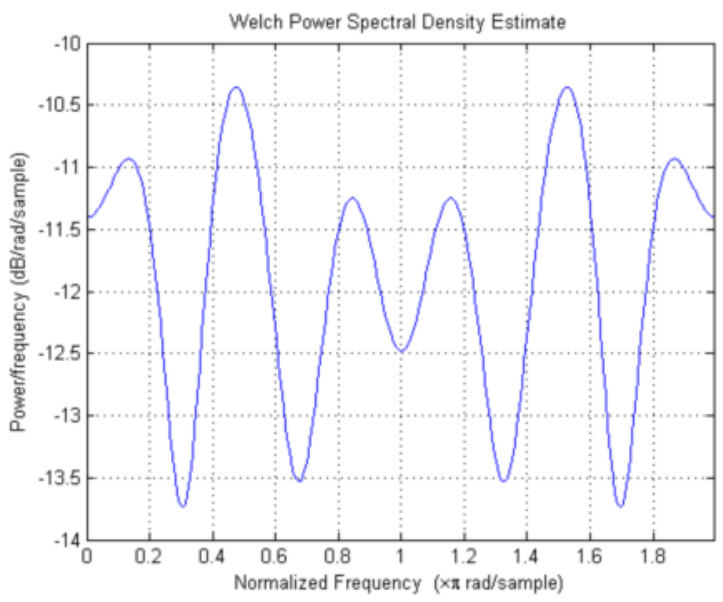

a-Inverse Safe Transform for 32 length data

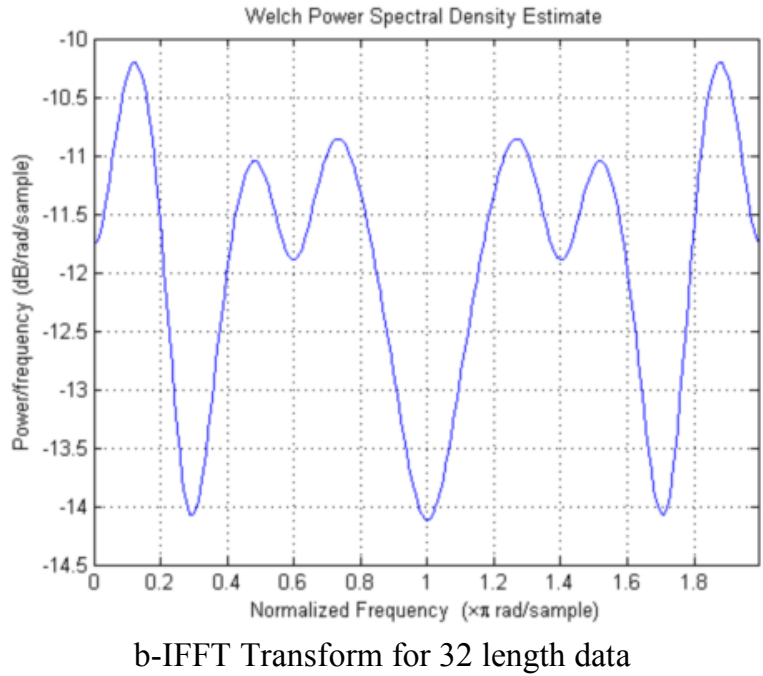

Figure 10. Power of the signals taken with the transformation. 
International Journal of

Soft Computing And Software Engineering (JSCSE)

e-ISSN: 2251-7545

Vol.2,No.6, 2012

Published online: Jun 17,2012

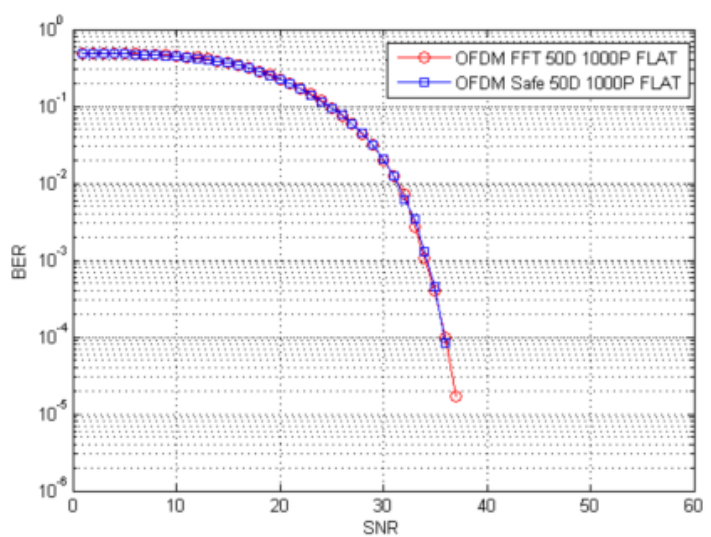

a- 4QAM with Doppler shift $50 \mathrm{~Hz}$ in selective channel

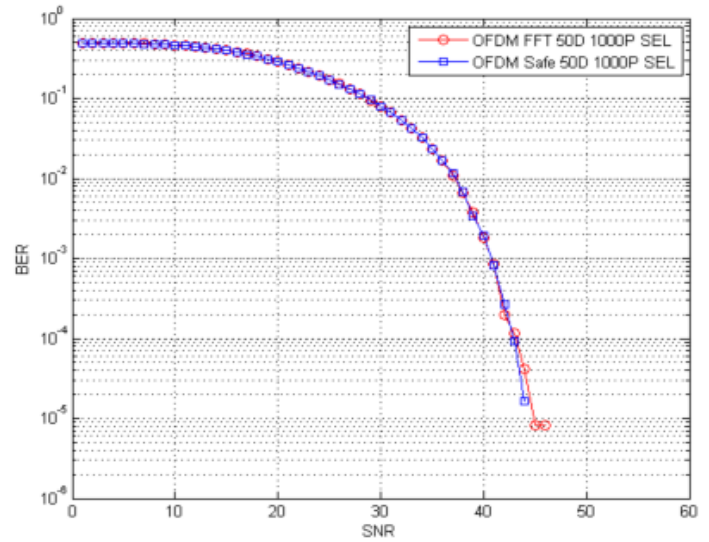

b- 4QAM with Doppler shift $50 \mathrm{~Hz}$ in flat channel

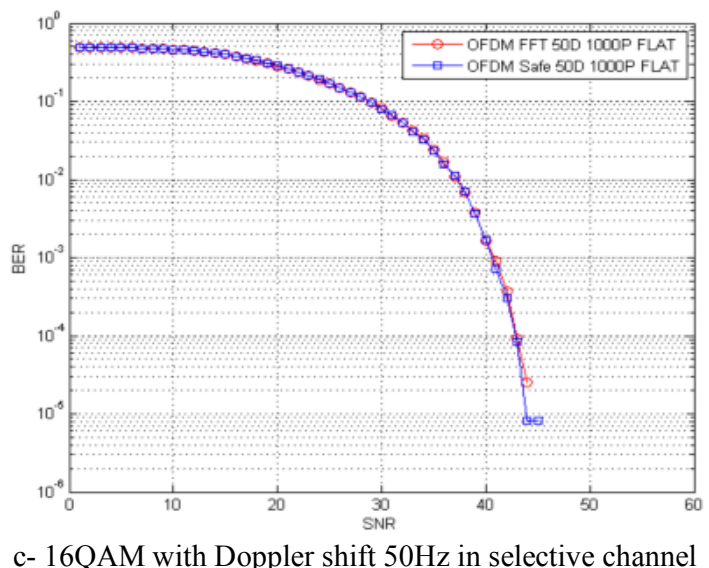

Figure 11. Transmitted data through wireless channel using OFDM. 
Published online: Jun 17, 2012

From the figure (8) it seen that the result is same then we find a new way to scrambling by change the phase of Safe matrix and easy way to create the matrix instead the FFT matrix with same power as shown:

$$
\begin{aligned}
& \mathrm{FFT}_{8 \times 8}=\left(\begin{array}{ccccccccc}
1 & 1 & 1 & 1 & 1 & 1 & 1 & 1 \\
1 & \frac{1}{\sqrt{2}}-\frac{1}{\sqrt{2}} \mathrm{j} & -\mathrm{j} & -\frac{1}{\sqrt{2}}-\frac{1}{\sqrt{2}} \mathrm{j} & -1 & -\frac{1}{\sqrt{2}}+\frac{1}{\sqrt{2}} \mathrm{j} & \mathrm{j} & \frac{1}{\sqrt{2}}+\frac{1}{\sqrt{2}} \mathrm{j} \\
1 & -\mathrm{j} & -1 & \mathrm{j} & 1 & -\mathrm{i} & -1 & \mathrm{j} \\
1 & -\frac{1}{\sqrt{2}}-\frac{1}{\sqrt{2}} \mathrm{j} & \mathrm{j} & \frac{1}{\sqrt{2}}-\frac{1}{\sqrt{2}} \mathrm{j} & -1 & \frac{1}{\sqrt{2}}+\frac{1}{\sqrt{2}} \mathrm{j} & -\mathrm{j} & -\frac{1}{\sqrt{2}}+\frac{1}{\sqrt{2}} \mathrm{j} \\
1 & -1 & 1 & -1 & 1 & -1 & 1 & -1 \\
1 & -\frac{1}{\sqrt{2}}+\frac{1}{\sqrt{2}} \mathrm{j} & -\mathrm{j} & \frac{1}{\sqrt{2}}+\frac{1}{\sqrt{2}} \mathrm{j} & -1 & \frac{1}{\sqrt{2}}-\frac{1}{\sqrt{2}} \mathrm{j} & \mathrm{j} & -\frac{1}{\sqrt{2}}-\frac{1}{\sqrt{2}} \mathrm{j} \\
1 & \mathrm{j} & -1 & -\mathrm{j} & 1 & \mathrm{j} & -1 & -\mathrm{j} \\
1 & \frac{1}{\sqrt{2}}+\frac{1}{\sqrt{2}} \mathrm{j} & \mathrm{j} & -\frac{1}{\sqrt{2}}+\frac{1}{\sqrt{2}} \mathrm{j} & -1 & -\frac{1}{\sqrt{2}}-\frac{1}{\sqrt{2}} \mathrm{j} & -\mathrm{j} & \frac{1}{\sqrt{2}}-\frac{1}{\sqrt{2}} \mathrm{j}
\end{array}\right) \\
& 0_{0} \mathbb{S}_{8 \times 8}=\left(\begin{array}{rrrrrrrr}
j & 1 & j & 1 & j & 1 & j & 1 \\
-1 & -j & -1 & -j & -1 & -j & -1 & -j \\
j & 1 & -j & -1 & j & 1 & -j & -1 \\
-1 & -j & 1 & j & -1 & -j & 1 & j \\
j & 1 & j & 1 & -j & -1 & -j & -1 \\
-1 & -j & -1 & -j & 1 & j & 1 & j \\
j & 1 & -j & -1 & -j & -1 & j & 1 \\
-1 & -j & 1 & j & 1 & j & -1 & -j
\end{array}\right) \text { (the sum of all element = zero) }
\end{aligned}
$$

But the favored one is ${ }_{-\pi / 2^{o}} \mathbb{S}_{\mathrm{n} \times \mathrm{n}}$ and ${ }_{\pi / 2^{o}} \mathbb{S}_{\mathrm{n} \times \mathrm{n}}$ because the inverse is the same matrix divided on the dimension:

$$
\left(-\pi / 2^{o} \mathbb{S}_{\mathrm{n} \times \mathrm{n}}\right)^{-1}=\left(-\pi / 2^{\mathrm{o}} \mathbb{S}_{\mathrm{n} \times \mathrm{n}}\right) / \mathrm{n}
$$

Example: ${ }_{-\pi / 2} \mathbb{S}_{2 \times 2}=\left(\begin{array}{cc}1 & -\mathrm{j} \\ \mathrm{j} & -1\end{array}\right),\left({ }_{-\pi / 2} \mathbb{S}_{\mathrm{n} \times \mathrm{n}}\right)^{-1}=\frac{1}{2} *\left(\begin{array}{cc}1 & -\mathrm{j} \\ \mathrm{j} & -1\end{array}\right)$

And ${ }_{-\pi / 2}{ }^{0} \mathbb{S}_{4 \times 4}=\left(\begin{array}{rrrr}1 & -j & 1 & -j \\ j & -1 & j & -1 \\ 1 & -j & -1 & j \\ j & -1 & -j & 1\end{array}\right)$

And ${ }_{0}{ }^{o} \mathbb{S}_{n \times n}, \pi^{o} \mathbb{S}_{n \times n}$ the inverse is $-{ }_{0} o \mathbb{S}_{n \times n} / n,-{ }_{\pi} o \mathbb{S}_{n \times n} / n$ respectively.

\section{Conclusions}

From this paper we find we can have orthogonal matrixes using complex number and it can be full orthogonal (elements by elements) that will help our in many applications like communications systems, (like CDMA $[9,10]$ ) and have infinite matrixes by shafting the phase, (it is hard to obtain 
International Journal of

Soft Computing And Software Engineering (JSCSE)

e-ISSN: 2251-7545

Vol.2,No.6, 2012

Published online: Jun 17, 2012

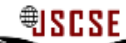

DOI: 10.7321/jscse.v2.n6.5

orthogonal matrix), from the application we find that Safe matrix is the same FFT matrix to find and performance and power but the sum of it is zero and more easy to find by tenser product.

\section{Reference}

[1] John Proakis , "Digital Communications", 4th edition McGraw-Hill 2000.

[2] Jennifer Seberry “On Orthogonal Matrices With constant Diagonal”, Department of Applied Mathematics, University of Sydney, Sydney, Australia. 1983

[3] K.G.BEAUCHAMP, "Application of Walsh and Related Functions with an Introduction to Sequence Theory” ACADEMIC PRESS, England, 1984

[4] David Damanik, Alexander Pushnitski, and Barry Simon, "The Analytic Theory of Matrix Orthogonal Polynomials" January 30, 2008.

[5] Saifuldeen Abdulameer Mohammed, "SPACE TIME BLOCK CODE FORPCC, MC-CDMA USING SLANTLET TRANSFORM" M.Sc Thesis, Electrical Engineering Department, College of Engineering, University of Baghdad, June 2007.

[6] IMRAN BAIG, VARUN JEOTI, “A NEW DISCRETE HARTLEY TRANSFORM PRECODING BASED INTERLEAVED-OFDMA UPLINK SYSTEM WITH REDUCED PAPR FOR 4G CELLULAR NETWORKS" Journal of Engineering Science and Technology Vol. 6, No. 6 (2011) $685-694$.

[7] Shilpi Gupta, Dr. Upena D. Dalal, "BER Performance For OFDM Using Non-Conventional Transform and Non-Conventional Mapping Schemes" International Journal of Emerging Technology and Advanced Engineering Website: www.ijetae.com (ISSN 2250-2459, Volume 2, Issue 3, March 2012).

[8] Parmar R. , Gupta S., Dalal U.D., "Comparison of BER Performances for Conventional and Non- Conventional Mapping Schemes Used in OFDM" International Conference on World Academy of science, Engineering and Technology. 2011. (79).733-736p.

[9] Victor M. Dasilva , Elvino S. Sousa, "Multi-Carrier Orthogonal CDMA Signals for QuasiSynchronous Communication Systems (1994)”, IEEE J. Select. Areas Commun., 1994

[10] Saifuldeen Abdulameer Mohammed, "Proposed System to Increase the Bits rat for User in the Chip packet using Complex number in Code Division Multiplexing Access and Pseudo Noise (JCDMA and JPN)" Proceeding of the Second Scientific Conference of Electrical Engineering University of Technology 4-5 April 2011 CE13 pages 200-211. 